\title{
LA NUEVA RUTA DE LA SEDA Y SUS IMPLICACIONES ECONÓMICAS Y GEOESTRATÉGICAS
}

Miriam Hermi Zaar ${ }^{1}$ Manuel-Blas García Ávila²

Resumen: La República Popular de China ha elaborado y puesto en marcha, a través de sus Planes Quinquenales, varios programas de desarrollo económico, entre ellos, los que dirigieron su transición hacia una economía de mercado. Sin embargo, ninguno había llevado implícito objetivos expansionistas y geoestratégicos tan claros, como los que encierra la Nueva Ruta de la Seda, cuyas ramificaciones conectarán los continentes asiático, europeo y africano. Su importancia en el actual escenario mundial, la convierte en el objeto central del análisis que permea este texto.

Palabras clave: China. 13ำ Plan Quinquenal. Proyectos geoestratégicos. Nueva Ruta de la Seda. ¿Un nuevo orden mundial?

\section{A NOVA ROTA DA SEDA E SUAS IMPLICAÇÕES ECONÔMICAS E GEOESTRATÉGICAS}

Resumo: A República Popular da China elaborou e realizou, a través dos seus Planos Quinquenais, vários programas de desenvolvimento econômico, entre eles, os que dirigiram sua transição a uma economia de mercado. Entretanto, nenhum deles havia levado implícito objetivos expansionistas e geoestratégicos tão claros, como os que contém a Nova Rota da Seda, cujas ramificações conectarão os continentes asiático, europeu e africano. Sua importância no atual cenário mundial, a converte no objeto central da análise que permeia este texto.

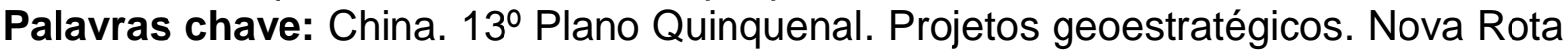
da Seda. Uma nova ordem mundial?

\section{ONE BELT, ONE ROAD AND ITS ECONOMIC AND GEOESTRATEGIC IMPLICATIONS}

Abstract: The People's Republic of China has developed and implemented, through its Five-Year Plans, various economic development programs, including those that directed its transition to a market economy. However, none of them had implicit expansionist and geostrategic objectives as clear, as those contained in the New Silk Road, whose ramifications will connect the Asian, European and African continents. Its importance in the current world scenario makes it the central object of the analysis that permeates this text.

Keywords: China. 13th Five-Year Plan. Geostrategic projects. New Silk Road. A new world order?

\footnotetext{
1 Universidad de Barcelona, Departamento de Geografía, Barcelona, España, miriamzaar@gmail.com, https://orcid.org/0000-0002-1717-8118

2 Investigador Independiente, Barcelona, España, manuelblasg@gmail.com, https://orcid.org/00000001-5388-7037
} 


\section{Introducción}

En la República Popular de China es el Partido Comunista quien decide, a través de sus congresos y de la aprobación de los Planes Quinquenales, las directrices a seguir en las esferas política, económica, social y geoestratégica.

Desde sus inicios en 1921, cuando el I Congreso fue realizado clandestinamente, al VII Congreso en 1956, el primero celebrado tras la fundación del régimen comunista en 1949, y hasta la actualidad, el Partido Comunista Chino ha ido adquiriendo matices diversos, aunque siempre orientados a lo que denominan "socialismo con características chinas".

Esto sucedió tanto en los programas Gran Salto Adelante (1958-1961) y Revolución Cultural (1966-1976) realizados en el período de Mao Tsé Tung, como con el reformista Deng Xiaoping, cuyo pragmatismo asociado a las reformas económicas, se hizo realidad en las Zonas Económicas Especiales (ZEE) y en los corredores de exportación, principalmente. También son una realidad en el actual gobierno de Xi Jinping, cuyas metas económica y geoestratégica, basadas en la innovación tecnológica, la producción y la exportación han impulsado la institución de una imbricada red de rutas terrestres y marítimas que conectan continentes, océanos, regiones, países y ciudades, y que se denomina One Belt, One Road (OBOR), Belt and Road Initiative (BRI), o sea la Nueva Ruta de la Seda.

Este artículo tiene como objetivo analizar la esencia del ambicioso proyecto (One Belt, One Road), así como sus implicaciones regionales y globales. Para ello, estructuramos el texto en tres apartados. Primeramente, presentamos unos breves apuntes sobre los principales hechos que marcaron la sociedad china tras el triunfo de la Revolución de 1949 y su transición hacia una economía de mercado volcada a la exportación. En un segundo apartado, como continuidad de las políticas que ya se venían poniendo en práctica y del contexto predecesor a la Nueva Ruta de la Seda, examinamos, el papel que China está desempeñando en el nuevo escenario mundial que rige el siglo XXI, así como los cambios ideológicos, políticos y geoestratégicos que han supuesto el traspaso de poder de la Cuarta a la Quinta generación de sus mandatarios. En un tercer apartado, y como cuestión principal de esta investigación nos centramos en el análisis de esta Nueva Ruta de la Seda. Teniendo presente los objetivos económicos y geoestratégicos chinos, estudiamos el contexto en el que este proyecto fue elaborado y la coyuntura en la que está siendo ejecutado, así 
como los mecanismos que son empleados por las empresas estatales chinas en los territorios donde estos "corredores de cooperación económica internacional", se establecen.

\section{La revolución China y su "transición al capitalismo" El período maoísta}

En líneas generales se puede afirmar que entre 1949 y el final de la década de 1970, los objetivos del Partido Comunista Chino, reflejados en las teorías maoístas y mediante los primeros Planes Quinquenales, estuvieron centrados en la instauración de un ambiente de estabilidad política y social, en reconstruir el sector productivo, y en contener la inflación.

Una de las principales medidas fue la legislación a favor de las mujeres, los jóvenes y los campesinos. Esto se observa en dos leyes aprobadas en 1950: a) la Ley del Matrimonio de $1^{\circ}$ de mayo de 1950 daba a la mujer los mismos derechos que al hombre en los ámbitos de la educación, el familiar, el laboral y el político, estimulando su participación en las actividades del nuevo régimen; b) la Ley de la Reforma Agraria de 30 de junio de 1950, que abolió la propiedad de los terratenientes, sustituyéndola en los años posteriores por cooperativas de producción agrícola.

Esta nueva coyuntura y el apoyo soviético posibilitaron a China un importante crecimiento en la producción de alimentos y en el sector industrial que, por primera vez, comenzó a fabricar camiones, tractores y barcos mercantes.

Sin embargo, la ruptura de las relaciones con la Unión Soviética -restablecidas oficialmente en 1989- y el proyecto Gran Salto Adelante (1958-1961), cuya meta era transformar la economía agraria en una economía industrial a través de comunas económicas autosuficientes y de la creación de centros fabriles, mediante la utilización de mano de obra intensiva, no dieron los resultados esperados. El gran desplazamiento de la población, los problemas climáticos, la falta de infraestructuras y el aislamiento del mercado mundial, provocaron una gran hambruna y, como consecuencia, la muerte de millones de chinos.

Un escenario de crisis que desembocó en la Revolución Cultural (1966-1976), una violenta reacción que pretendía eliminar los rasgos tradicionales y capitalistas que todavía existían en la sociedad china. Muchos adeptos al capitalismo (políticos, funcionarios públicos, miembros del ejército, trabajadores urbanos, etc.), fueron 
perseguidos, presos, sometidos a trabajos forzados e incluso torturados y asesinados por sus ideas. También se expropiaron todas las propiedades y se prohibieron las actividades mercantiles privadas. La economía se planificó al 100\%.

Con el fallecimiento de Mao Tse Tung (1893-1976) y tras varios años de estancamiento económico, el XII Congreso del Partido Comunista de China de 1982 puso fin oficialmente al período maoísta. China pasó a ser liderada por el reformista Deng Xiaoping (1904-1997) que bautizó su nueva etapa de gobierno como "protosocialismo" o "socialismo en su primera fase".

\section{Deng Xiaoping en el poder}

Como parte de este nuevo proyecto político y económico, Deng Xiaoping puso en marcha un eficaz programa de reformas que pretendía desarrollar las fuerzas productivas a través de la modernización de la agricultura y de la industria, y de la inversión en educación, ciencia y tecnología. Para ello, aprobó normativas que retiraron las restricciones a la iniciativa privada, otorgaron una cierta autonomía a sus regiones, y abrieron el país al mercado externo.

Estas medidas llevaron a la ansiada revolución industrial, que tomó forma en sus Zonas Económicas Especiales (ZEE) situadas en el valle del río Yangtzé y en las regiones central y litoral sudoriental. Las compañías extranjeras que quisiesen participar en ellas deberían compartir sus conocimientos tecnológicos con las empresas estatales chinas, a cambio de incentivos fiscales o exenciones de impuestos estatales.

El objetivo era estimular la competencia entre las empresas estatales, fomentar la innovación mediante la transferencia de tecnología y la aportación de los recursos necesarios para el crecimiento económico del país. Con esto logró, por ejemplo, en el área de la comunicación, consolidar la marca Huawei como el primer actor internacional de China en este sector. Esto se obtuvo mediante el trabajo de miles de ingenieros chinos y estableciendo redes para la venta de productos en Asia, Oriente Próximo y Rusia, inicialmente a precios módicos para introducirse en el mercado.

La política de Deng Xiaoping también previó la creación de un nuevo sistema financiero y tributario en el que la figura impositiva principal pasó a ser el impuesto sobre el valor agregado. De este modo, se separaron las finanzas de carácter 
político, es decir, los impuestos directos, de los de carácter comercial, y se reforzó el papel del mercado como medio de distribución de recursos. Esto favoreció tanto a las zonas de apertura y de desarrollo económico, como a la descentralización de las decisiones, dejando que cada una de las provincias o municipios elaborasen sus planes económicos (Belluga Capilla, Gómez de Ágreda, s/f, p. 52). También impulsó el comercio exterior, que pasó de representar el $7 \%$ del PIB chino en 1978 , al $40 \%$ del mismo en la década de 1990.

En el ámbito rural también se produjeron amplias reformas, realizadas en tres fases y que culminaron con la imposición del sistema de responsabilidad familiar. La primera de ellas (1978-1984), implicó el desmantelamiento de las comunas, la introducción de un nuevo sistema de producción, el surgimiento de los mercados libres y la diversificación de la producción rural. La segunda fase (1984-1992), se caracterizó por una mayor inversión en recursos y la reorganización de la distribución del ingreso, a fin de proteger a las familias con poca mano de obra masculina, además, se intentó resolver el problema del desempleo rural, estimulando la creación de pequeñas empresas locales, lo que resultó una verdadera revolución en la estructura de la producción industrial del país. La tercera fase, iniciada en 1993, se diferenció por la creación de infraestructuras e instituciones financieras de estímulos a la inversión en las actividades agrarias, y se pusieron en marcha mecanismos para la mejora de la productividad y distribución de los alimentos (Cornejo, 2001, p. 79 y sig.).

Estas y otras medidas, basadas en las directrices establecidas en los Planes Quinquenales, fueron las que posibilitaron la construcción de un tipo particular de economía de mercado que incorporó de manera progresiva elementos del neoliberalismo capitalista imbricados con un control autoritario centralizado. Es así como David Harvey entiende las inversiones chinas en mega proyectos destinados a transformar las infraestructuras físicas del país. Sus objetivos, según este autor, fueron similares a los de Estados Unidos durante el keynesianismo de las décadas de 1950 y 1960, con la construcción de su sistema interestatal de autopistas: los de absorber los excedentes de capital y de mano de obra existentes, mediante el endeudamiento del Estado (2007, p. 131-147).

Se trata de un argumento oportuno para explicar cómo los avances tecnológicos chinos engendraron muchas de las contradicciones capitalistas -entre ellas las desigualdades territoriales y sociales y la degradación medioambiental-, 
reproducidas sistemáticamente, en un país ávido de libertades y derechos políticos, como quedó de manifiesto por la represión en la plaza de Tiananmen el 4 de junio de 1989.

Las desigualdades sociales y territoriales están muy presentes en China. A pesar de las reformas llevadas a cabo entre las décadas de 1970 y 1990, las zonas rurales, donde vive aproximadamente el $40 \%$ de la población, continúan siendo las más pobres del país y en su mayoría dependen de las remesas particulares de dinero enviadas desde las zonas urbanas e industriales para la supervivencia de sus habitantes. La disolución de las comunas y la perdida de los derechos sociales obtenidos con las mismas, como educación y salud, el estancamiento de los salarios y la demanda de mano de obra industrial condujo a un intenso proceso de migración rural-urbano, involucrando a cerca de 200 millones de campesinos, utilizados como reserva de mano de obra en los centros industriales, con largas jornadas laborales, bajos salarios y sin protección social, hasta la actualidad.

Además, son de conocimiento general los problemas medioambientales que este país genera y padece, como la contaminación del aire, de los ríos y del suelo, la deforestación y sus consecuencias, como la destrucción de los ecosistemas -por lo que se supone que ha sido el origen de la expansión del SARS-CoV-2 (Zaar, García Ávila, 2020)-, derivados de la falta de concienciación y de la adopción de políticas que incentiven las energías limpias. Según William Laurance, biólogo y profesor de la Universidad australiana James Cook "es difícil encontrar un rincón del mundo en desarrollo donde China no tenga un impacto ambiental significativo" (28/03/2017).

En su conjunto, este escenario nos hace concordar con David Harvey, cuando afirma que las reformas chinas no habrían adquirido tanta relevancia, ni habrían registrado tantos avances, si en el mundo capitalista avanzado no se hubieran producido cambios de gran importancia en el modo de funcionamiento del mercado mundial, como fue el impulso que tuvieron las políticas neoliberales en el comercio internacional durante las décadas de 1980 y 1990 (2007, p. 131-132).

\section{China en la nueva coyuntura del siglo XXI}

La coyuntura política global en el siglo $X X I$ se dibuja bajo una perspectiva diferente a la del siglo XX, cuando EEUU se autoproclamaba árbitro en los principales conflictos y divergencias internacionales. Sus características parecen más bien, las de un orden político de tipo multipolar, lo que ha dado a China una 
cierta flexibilidad para defender sus tesis en los asuntos mundiales más significativos.

Esto se refleja en los $10^{\circ}, 11^{\circ}, 12^{\circ}$ y $13^{\circ}$ planes quinquenales (2001-2005, 2006-2010, 2011-2015 y 2016-2020, respectivamente) que, además de avanzar en la optimización de la estructura industrial y la utilización de sus recursos, amplía sus lazos comerciales con el exterior, a través del establecimiento de un consistente y moderno sistema empresarial. Para ello, el aumento de los aportes en educación, ciencia y tecnología han sido imprescindibles, ya que han fomentado la innovación como instrumento para impulsar el desarrollo del país.

La incorporación de China a la Organización Mundial del Comercio, en diciembre de 2001 le está obligando a respetar la propiedad intelectual, porque existen sospechas de ciberataques a instituciones científicas, incluso relacionadas con la vacuna para combatir la Covid-19.

En los últimos veinte años, las solicitudes chinas de registros de patentes internacionales en la Organización Mundial de la Propiedad Intelectual (OMPI) ha crecido un $200 \%$, con buena parte de los registros en el área tecnológica, y con Huawei en cabeza en los últimos años. En 2019, China fue el país que más patentes registró (58.990), por delante de Estados Unidos y Japón, que quedaron en la segunda y tercera posiciones, respectivamente.

Se trata de un proceso que gana impulso si tenemos en cuenta los objetivos del XVII Congreso del Partido Comunista Chino realizado en octubre de 2007: la preparación de la transición de la Cuarta a la Quinta generación de dirigentes comunistas, que según Daniel Gomá (2008) presenta diferencias notables. Una de ellas es que, mientras los integrantes de la Cuarta eran en su mayoría tecnócratas, con formación en ingenierías, los dirigentes de la Quinta generación, además de una formación tecnológica, poseen masters y doctorados en el ámbito de las Ciencias Sociales (Derecho, Económicas, Ciencias Políticas, etc.).

Jiang Zemin y Hu Jintao, Secretarios Generales del Partido Comunista Chino entre 1989-2002 y 2002-2012 y presidentes de la República Popular China entre 1993-2003 y 2003-2013, respectivamente, son ejemplos de políticos de Tercera y Cuarta generaciones, cuya formación en ingenierías influyó decisivamente en las políticas de desarrollo tecnológico. La estratégica económica de sus gobiernos reflejó este contexto: "China se concentrará en el desarrollo de alta tecnología y la promoción de la informatización de la economía y la sociedad, la industrialización 
con tecnología de la información. Tenemos que conseguir un gran salto tecnológico" (Bregolat, 2014, p. 27).

A su vez Xi Jimping (Quinta Generación), tuvo una formación universitaria más amplia: Ciencias Sociales y Síntesis Orgánica Básica (una rama de las ingenierías), que complementó especializándose en Teoría Marxista, Educación Ideológica y Política, y doctorándose en Derecho.

Otra diferencia es que la Quinta generación de dirigentes comunistas posee una mejor preparación en política internacional, dominan el idioma inglés y han mantenido relaciones con estudiantes, investigadores y empresarios occidentales, lo que les hace más pragmáticos y preparados (Gomá, 2008).

En esta nueva coyuntura las actuales perspectivas geopolíticas internacionales de China han sufrido algunos cambios, respecto a las anteriores. Mientras Hu Jintao consideraba que la meta era "construir un mundo armonioso de paz duradera y prosperidad común", una comunidad global en la que coexistan diferentes civilizaciones, los discursos de Xi Jinping, por su diferente formación ideológica y política, se centran en la difusión de la identidad china como idea global -el "sueño de China" que moviliza el "espíritu chino", la "fuerza china", la "senda china" a la "solución de China"-, desde una estrategia de Estado. En este futuro escenario, el sueño estadounidense mundial resultaría sustituido por el sueño chino, la occidentalización por la orientalización y el excepcionalismo estadounidense por el excepcionalismo chino, en el que sería muy difícil compartir valores (Callaham, 02/10/2019).

Este nuevo paradigma sinocéntrico, queda muy evidente si analizamos el $13^{\circ}$ Plan Quinquenal para el Desarrollo Económico y Social Nacional de la República Popular China, aprobado por el XII Congreso Popular Nacional, el 5 de marzo de 2016, seis meses antes que la ciudad de Hangzhou presidiese por primera vez la cumbre del G20.

En este $13^{\circ}$ Plan Quinquenal se observa como la tecnología y la innovación continúan siendo la fuerza motriz y la línea guía del desarrollo del país. Todos los temas tratados en los capítulos $4^{\circ}$ al $10^{\circ}$ aluden a la importancia de la innovación científica y tecnológica para el desarrollo de todos sus sectores productivos y estratégicos (industriales, agrícolas, de biomedicina, infraestructuras, energía, empresarial, exportación, información y seguridad nacional o aeroespacial, etc.) 
incluyendo, en el capítulo 8oㅡ, el compromiso de crear mecanismos institucionales que estimulen la innovación.

Estas iniciativas han sido puestas en marcha a través de "Made in China 2025", cuyo propósito es promover una profunda integración de las tecnologías de la información y de la producción, hacia un desarrollo industrial "de alta gama, inteligente, verde, aportando nuevas ventajas a la competencia manufacturera" (13ํㅜ Plan Quinquenal, 2016, Capítulo 23ㅇ).

Sin embargo, y a pesar del gran empeño que China demuestra en el sector

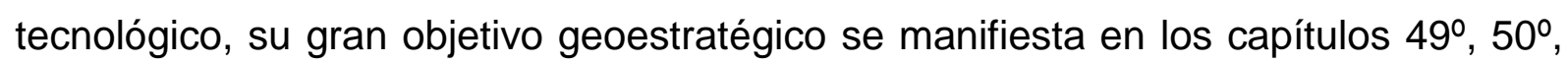
$51^{\circ}$ y $52^{\circ}$ del $13^{\circ}$ Plan Quinquenal, bajo los títulos: "Mejorar el trazado estratégico de la apertura al mundo exterior", "Mejorar el nuevo sistema de apertura al mundo exterior", "Promover la construcción del One Belt, One Road" y "Participar activamente en la gobernanza económica mundial", respectivamente. En ellos, las principales metas son: a) el refuerzo de las infraestructuras que posibiliten la construcción de corredores de cooperación económica (exportación e importación) desde transportes multimodales transfronterizos entre China y otros países asiáticos, europeos y africanos, en los que se tienen en cuenta políticas de desarrollo para las regiones chinas más pobres y poco comunicadas; b) la internacionalización de sus instituciones financieras y el fortalecimiento de los puntos de venta en el extranjero; c) participar activamente en el desarrollo de normas internacionales; d) promover la reforma del sistema internacional de gobernanza económica, mediante una destacada actuación en las principales plataformas de cooperación regional y de organización mundial. Una señal clara del papel que China quiere jugar en el mundo en el siglo XXI.

Se trata de una coyuntura que cambia en mucho la visión que se tenía de China a inicios del siglo XXI, como una potencia regional y un atractivo que residía en su gran peso poblacional y territorial, en la importancia de sus recursos naturales y la magnitud de su PIB (Anguiano, 2001, p. 269).

Teniendo en cuenta estos objetivos chinos, nos detenemos en el próximo apartado, en el análisis del proyecto One Belt, One Road y cómo sus mecanismos contribuirán decisivamente a que China alcance los objetivos del $13^{\circ}$ Plan Quinquenal, probablemente muy similares a los que integrarán el 14ㅇ Plan Quinquenal, que será aprobado por el XIII Congreso Popular Nacional, en 2021. 


\section{Contexto en el que se está proyectando y ejecutando el one belt, one road (La Nueva Ruta de la Seda)}

En las dos últimas décadas, China ha protagonizado tres procesos clave que han supuesto un cambio fundamental en el mapa geoestratégico global. En 2001, después de recuperar Hong Kong (1997) y Macao (1999), últimos grandes vestigios coloniales territoriales de occidente, China, en alianza con Rusia y otros países de Asia Central logró la consolidación de la Organización para la Cooperación de Shanghái (OCS), que funciona como contrapeso a la OTAN y a EEUU. En 2009 se produjo el lanzamiento del BRICS (Brasil, Rusia, India, China y Sudáfrica) con la primera cumbre realizada en Ekaterimburgo (Rusia), en la que se articularon en un bloque las potencias industriales de la semi-periferia, buscando reconfigurar el orden mundial existente.

El tercer proceso se inició en 2013 cuando Pekín divulgó la iniciativa "Nueva Ruta de la Seda" -frente a las estrategias fomentadas por EEUU y sus aliados-, con la que impulsa una nueva estructura financiera a escala global, a través del Banco Asiático de Inversión e Infraestructura y del Banco de los BRICS, que reducen la importancia de instituciones internacionales como el FMI y el Banco Mundial; y estrecha las alianzas con Rusia y otros países europeos, asiáticos, y africanos.

La Nueva Ruta de la Seda surge como la marca más potente de este nuevo rumbo político, económico y geoestratégico de China. Se trata de construir y consolidar el One Belt, One Road (OBOR), declarado por la cúpula del Partido Comunista una prioridad de la política exterior china, por los motivos que examinamos a continuación.

Como resultado de la guerra comercial con EEUU y la ralentización de la economía global, el crecimiento económico chino de los últimos años, aun siendo alto, ha sido el menor desde 1990. Su PIB creció un $6,6 \%$ en 2018 y un $6,1 \%$ en 2019, sus peores datos desde 1990 -en 2007 fue del 11,4\%-. Se trata de un nuevo escenario que ha provocado despidos en las industrias manufactureras, aumentado el desempleo y las desigualdades sociales, llevando a crecientes tensiones internas, razón por las que es imprescindible que el gobierno chino se apresure a buscar nuevos "motores" que desarrollen sus regiones interiores, reduzcan las migraciones internas y reactiven su macroeconomía, lo que mitigaría las tensiones sociales. 
Además, es esencial mejorar el comercio intrarregional. A pesar de los esfuerzos del Estado chino para crear alianzas regionales y provinciales, las grandes inversiones en infraestructuras de comunicación, las mercancías y el capital no fluyen fácilmente de un extremo al otro del país. Algunas provincias mantienen relaciones comerciales mucho más intensas con el exterior que con sus propias regiones.

Bajo la perspectiva geoestratégica, China proyecta su influencia más allá de su entorno, tomando posiciones en Eurasia, África y América Latina.

La Nueva Ruta de la Seda asegura a China, a través de sus fijos y flujos, un acceso seguro a los océanos Pacífico e Índico y al Mar Mediterráneo. Es importante recordar que, en 2019 , el $17,1 \%$ de las exportaciones chinas se destinaron a la Unión Europea, lo que convierte a esta en el mercado exterior chino más importante, por delante de Estados Unidos y de la Asociación de Naciones del Sudeste Asiático (Zenglein, 10/07/2020).

Asimismo, esta Nueva Ruta posibilita a China incrementar su influencia, sin depender exclusivamente de su principal itinerario marítimo, el estrecho de Malaca, por el que pasa más del $80 \%$ de sus exportaciones.

Este estrecho se ha transformado en una de las áreas más estratégicas del planeta, en uno de sus centros de gravedad, tanto en lo económico y comercial, como en lo militar y estratégico, razón por la que es una región marcada por conflictos territoriales y la fuerte presencia de EEUU, país con quién se han recrudecido las tensiones durante los años 2019 y 2020, a través de una "guerra comercial" de aranceles y de la troca de acusaciones sobre el origen del SARS-CoV2 (Zaar, 2020). La búsqueda de trayectos alternativos protegería a China de eventuales bloqueos estadounidenses.

Desde una coyuntura política, militar y estratégica, China, que ha emergido como una potencia global, le disputa en muchos ámbitos la hegemonía a los EEUU y aspira ser el país con mayor envergadura a mediados del siglo XXI. Del mismo modo que Rusia ha recuperado su ambición zarista y comparte con China su rechazo a un orden internacional conformado por Occidente y liderado por Estados Unidos, ambas potencias comparten su voluntad expansionista y una creciente agresividad diplomática, económico/comercial y militar (Piqué, 18/02/2020).

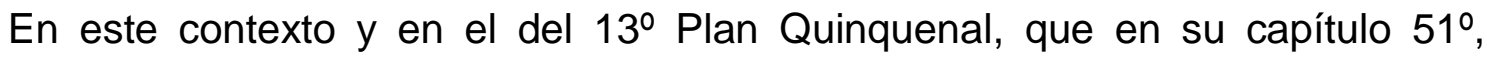
sesión I, deja claro cuáles son los territorios prioritarios para la construcción de 
infraestructuras que posibiliten poner en marcha lo que se denomina como "corredores de cooperación económica internacional", analizamos a continuación, el proceso de consolidación de esta ruta, tanto a partir de los acuerdos realizados entre los territorios pertinentes, cómo respecto a las infraestructuras que están realizándose o en proyecto, con el objetivo de ampliar la conexión entre las subregiones asiáticas, y entre Asia, Europa y África en dos vías básicas, una terrestre y otra marítima.

\section{La Nueva Ruta de la Seda, sus características e implicaciones económicas y geopolíticas}

One Belt, One Road, Belt and Road Initiative (BRI) o Nueva Ruta de la Seda es un gran proyecto internacional lanzado por China en 2013. Declarado prioridad por la Cúpula del Partido Comunista Chino, este plan tiene el propósito de rescatar y ampliar la relevancia que tenía la Antigua Ruta de la Seda, una red de vías comerciales que conectaba el comercio y la cultura oriental y occidental entre los siglos I a.C. y XIV.

Organizada para hacer posible el comercio de la seda china se extendía por todo el continente asiático, conectando China con Mongolia, el subcontinente indio, Persia, Arabia, Siria, Turquía, Europa y África (figura 1).

Figura 1- La Antigua Ruta de la Seda en el siglo I d. de C. y sus principales vías

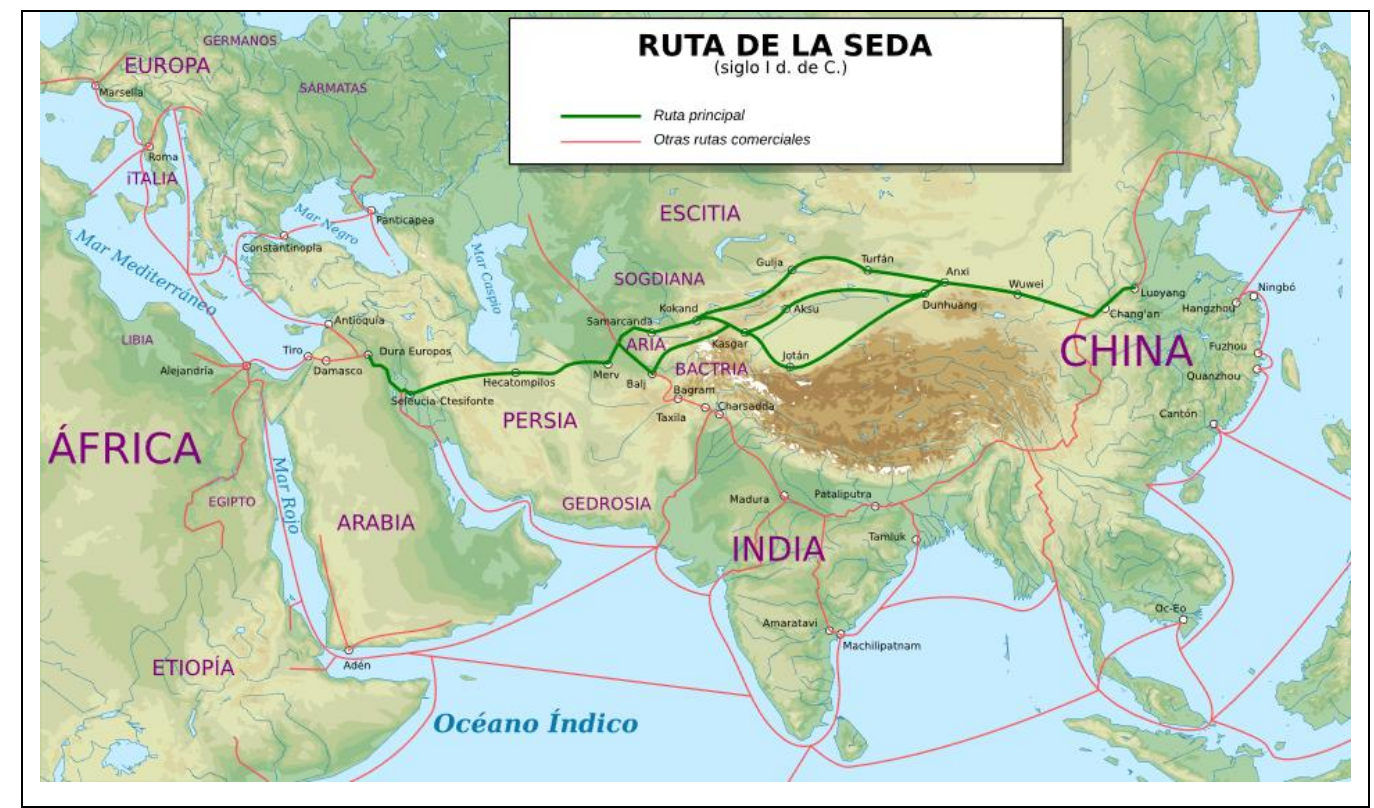

Fuente: Wikipedia.org. Adaptado por los autores. Disponible en

<https://es.wikipedia.org/wiki/Ruta_de_la_seda\#: :text=La\%20Ruta\%20de\%20la\%20Seda\%20fue\%2 Ouna\%20red\%20de\%20rutas,\%2C\%20Turqu\%C3\%ADa\%2C\%20Europa\%20y\%20\%C3\%81frica.>. Acceso en 15 jun 2020. 
La Nueva Ruta de la Seda, se transforma, por un lado, en un instrumento que amplía las posibilidades comerciales chinas, a través de la diversificación de sus itinerarios, abriendo nuevos mercados de consumo para los productos que no encuentran salida en su mercado doméstico. Se calcula que la Ruta de la Seda del siglo XXI conectará a más de 60 países, lo que supondrá una base de consumo de 4.400 millones de personas -aproximadamente el $63 \%$ de la población mundial-, que aglutina casi el 30\% de la economía global- (Quintana, 14/05/2018). Además, los cargueros chinos podrán transportar hasta un $75 \%$ del suministro energético que demanda su economía.

Por otro lado, supone un ambicioso planteamiento 'geopolítico' -término que Yves Lacoste utiliza para designar la influencia que unos Estados ejercen sobre los territorios o sobre las poblaciones en que viven-, y que China conduce mediante acuerdos bilaterales que viabilizan la realización de un gran número de infraestructuras en áreas que, por su posición geográfica o sus recursos naturales, son consideradas estratégicas.

De este modo, la Nueva Ruta de la Seda se transforma en un amplio campo para las inversiones chinas, realizadas a través de la compra o de la concesión de un gran número de infraestructuras marítimas y ferroviarias, en los principales puntos de paso de ambas rutas, y mucho más allá.

Estas inversiones -que podrían llegar a 8.000 millones de dólares-, son realizadas principalmente por empresas públicas mediante fondos gubernamentales, provenientes del Fondo de la Ruta de la Seda, dotado con 40.000 millones de dólares y fundado conjuntamente por la Corporación de Inversión de China (el fondo soberano chino más importante), el Banco de Exportación-Importación de China y el Banco de Desarrollo de China. También cuenta con el apoyo financiero de otras instituciones, como el propio Banco Asiático de Inversión en Infraestructuras, el China-ASEAN Investment Cooperation Fund y el China-Eurasia Economic Cooperation Fund (Esteban y Otero-Iglesias, 09/04/2015).

Las grandes infraestructuras, situadas a lo largo de los corredores económicos terrestres y marítimos combinados a partir de China, conectan varios países asiáticos, de Oriente Medio, de Europa y de África con este país y entre sí, lo que supone para China, importantes mejoras en sus conexiones exteriores y una mayor influencia económica y política a nivel mundial (figura 2). 
Figura 2- Las Rutas de la Seda Terrestre y Marítima y sus ramificaciones

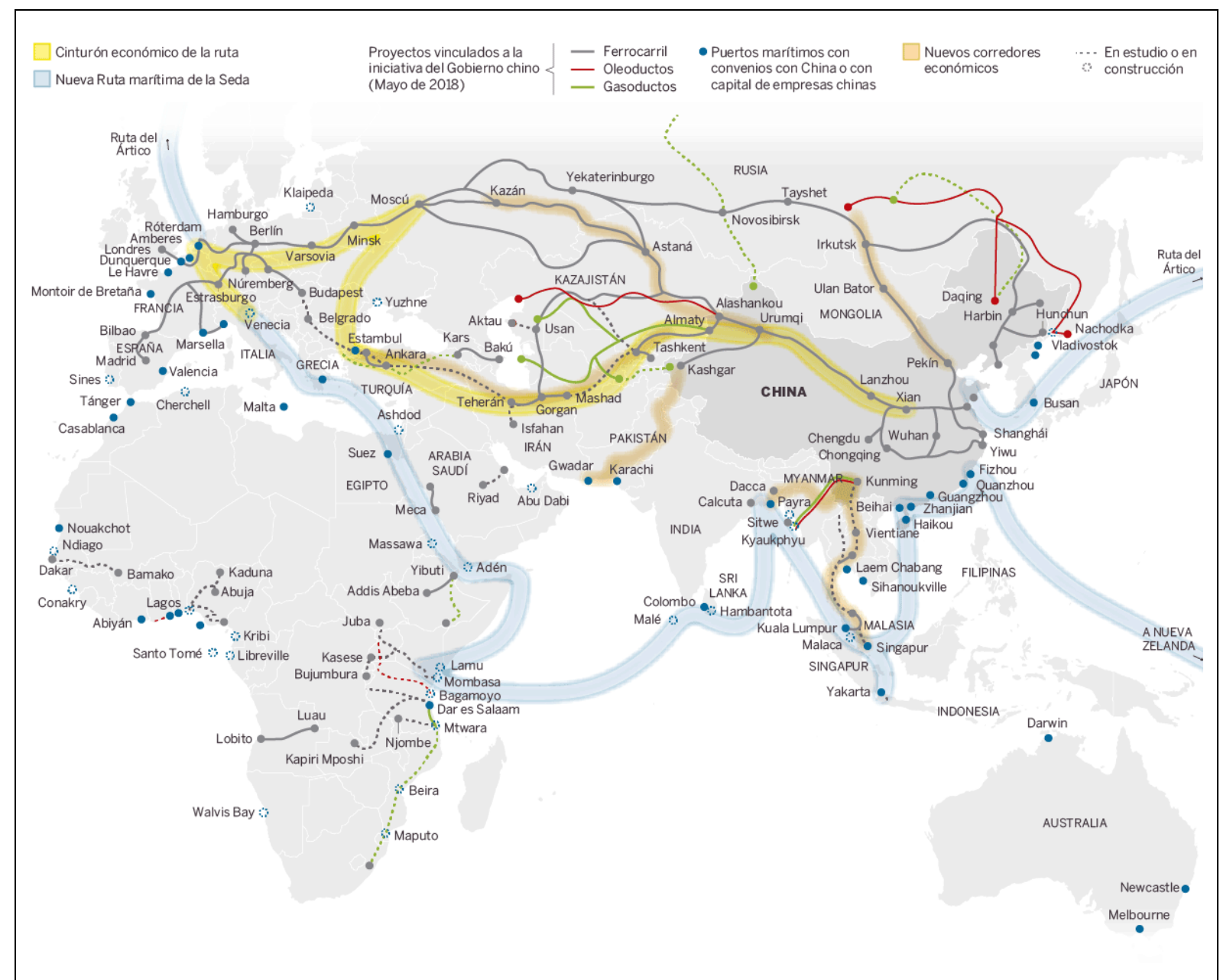

Fuente: Instituto Mercator para estudios sobre China (MERICS). Disponible <https://merics.org/en>. Acceso 10 jun 2020.

Estas son algunas de las razones por las que expertos y proveedores internacionales de soluciones logísticas como Bernhard Simon entienden la Nueva Ruta de la Seda como un instrumento que convertirá a China en la gran potencia del siglo XXI. Según Simon "en términos políticos, los pasillos comerciales entre China y Europa, así como África, parecen ser la clave para que China se convierta en una potencia mundial líder en el siglo XXI" (16/01/2020).

\section{Belt and Road Initiative (BRI) y su "Collar de perlas": La Ruta de la Seda (marítima)}

La Ruta de la Seda Marítima se ha ido consolidando a medida que las empresas estatales chinas han ido logrando el control de estructuras portuarias con posición estratégica en el Océano Índico, Canal de Suez y Mar Mediterráneo, mediante concesión o compra. Estas corporaciones y sus plantas logísticas se han 
transformado en un complejo engranaje de distribución de productos chinos hacia otros mercados, posibilitando que se intercambiasen en 2019, entre Europa y Asia, cerca de 25 millones de contenedores de mercancías.

Para ello, China ha encauzado una gran parte de sus inversiones hacia los puertos de Shanghái, Yiwu, Fizhou, Quanzhou, Guangzhou, Zhanjian, Beihai, Haikou, localizados en los mares de China Oriental y de China Meridional, -este último mar reclamado internacionalmente como territorio chino-, y también hacia otros puertos situados en el eje principal de esta ruta marítima:

a) Mar de Japón: los puertos de Vladivostok y Nachodka (Rusia) y el puerto de Buzan en Corea del Sur;

b) Golfo de Tailandia: puertos de Sihanoukville (Cambocha) y Laem Chabang (Tailandia);

c) Estrecho de Malaca: puertos de Singapur y Kuala Lumpur (Malasia);

d) Mar de Java: puerto de Jakarta (Indonésia);

e) Mar de Timor: puerto de Darwin (Austrália);

f) Mar del Coral: puertos de Newcastle y Melbourne (Australia);

g) Golfo de Bengala: puertos de Sitwe (Myanmar), Payra Port (Bangladesh) y Hambantota (Sri Lanka);

h) Costa índica africana: puertos de Bonbasa y Lamu (Kenia);

i) Mar Arábico: puertos de Malé (Maldivas), Karachi y Gwadar (Paquistán);

j) Gofo Pérsico: puerto de Abu Dhabi (Emiratos Árabes Unidos);

k) Mar Rojo: puertos de Adén (Yemen), Massawa (Eritrea) y Suez (Egipto);

l) Mar Mediterráneo: puertos de Ashdob (Israel), Pireo (Grecia) y Venecia (Italia) (figura 2).

Para garantizar el funcionamiento y la autonomía de esta ruta, de modo que atienda los intereses chinos, además de las concesiones obtenidas o la adquisición de infraestructuras, varias compañías dirigidas por las empresas gubernamentales China Ocean Shipping Company (COSCO) y China Merchants Group, administran terminales portuarias en los principales estrechos marítimos de esta ruta: Malaca, Ormuz, Gibraltar y Suez.

Como ejemplo de este nuevo procedimiento de gestión y adquisición de infraestructuras marítimas por parte del gobierno chino, se pueden señalar dos casos, uno en Grecia, que se transforma en una importante puerta de la Ruta Marítima de la Seda, y otro en España. 
En abril de 2016, el primer ministro griego Alexis Tsipras firmó un contrato de venta del 67\% de la empresa gestora del Puerto del Pireo, el mayor de Grecia, a la estatal china COSCO, por un valor de 368,5 millones de euros, con el compromiso chino de invertir una cantidad similar -350 millones de euros- en el mismo hasta 2026. A esta negociación se suma la concesión por 35 años de dos terminales operadas también por COSCO que, a su vez, se compromete a invertir 200 millones de euros en su ampliación.

La adquisición de estas infraestructuras, ha posibilitado a China construir un centro logístico, desde el que se coordina un tráfico superior a los cinco millones de contenedores anuales, lo que facilita sobremanera la entrada y distribución de sus productos -como Huawei y ZTE-, en toda Europa. La planificada construcción de un tren de alta velocidad desde Atenas hasta Budapest, vía Skopje y Belgrado, también está siendo decisiva a la hora de crear nuevos enlaces de comercio entre Europa Central y Asia a través de Grecia y los Balcanes (Müller-Markus, 2016).

En el ámbito geoestratégico, según Eurochinabridge (2017) la adquisición de estas infraestructuras posibilita que China se encargue del mantenimiento y reparación de equipos militares griegos en Creta, lo que abre la perspectiva de participar también en controles navales conjuntos en el Mediterráneo.

En España, de los puertos más importantes (Algeciras, Valencia, Barcelona, Bilbao, Vigo y Las Palmas), tres están controlados por la estatal COSCO, los de Valencia, Barcelona y Bilbao. En 2006, la Autoridad Portuaria de Barcelona (APB) adjudicó a la empresa china Hutchison Ports Holding la construcción y la gestión por un período de 30 años de la nueva Terminal de contenedores del Puerto de Barcelona. Para la ejecución de esta obra y la gestión de las operaciones portuarias, Hutchison y el grupo catalán Mestre formaron una nueva sociedad, la TerCat, participada al $70 \%$ por el grupo chino.

En 2017 COSCO adquirió la mayoría accionarial (51\%) de Noatum Ports, rebautizada como Cosco Shippings Ports Spain, por 197 millones de euros. Esta operación, posibilitó a la compañía asiática controlar las principales terminales de contenedores de los puertos de Valencia y Bilbao, bajo la denominación de CSP Iberian Valencia Terminal y CSP Iberian Bilbao Terminal, respectivamente. En este último, situado en el Mar Cantábrico, invirtió 10 millones de euros en su terminal ferroviaria, desde la que pretende operar con trenes de mercancías que conecten 
con sus otras terminales interiores, como las de Puerto Seco de Coslada (Madrid) y de Zaragoza (Cosco Spain, 2019).

Además, de los puertos situados en el eje principal de la Ruta de la Seda Marítima, China adquirió un porcentaje significativo de las estructuras portuarias incluso más del 50\%-, en un gran número de países de todos los continentes, en las que está realizando importantes inversiones y que podrán integrarse a esta Ruta cuando lo consideren oportuno:

a) Mar Mediterráneo: puertos de Marsella (Francia), Malta (Malta), Cherchel (Argelia) y Valencia (España);

b) Mar del Norte: puertos de Amberes (Bélgica) y Róterdam (Países Bajos);

c) Mar Báltico: puerto de Klaipéda (Lituania);

d) Océano Atlántico: puertos de Sines (Portugal), Montoir de Bretagne, El Havre y Dunquerque (Francia), Tánger y Casablanca (Marruecos), Nuakchot y Ndiago (Mauritania), Conakri (Guinea), Lagos (Nigeria), Santo Tomé y Príncipe, Libreville (Gabón) y Walvis Bay (Namibia);

e) Océano Índico: puertos de Dar el-Salam, Mitwara y Bagamoio (Tanzania), Maputo y Beira (Mozambique) (figura 2).

En este proceso, lo que más llama la atención es que, mientras China logra concesiones y compra participaciones mayoritarias en diversos puertos europeos, gestionándolos o controlando un porcentaje significativo de su capacidad en las terminales de contenedores, ningún operador europeo posee mayoría en las acciones de los puertos chinos, a pesar de ser Europa el destino principal de los contenedores que parten de dichos puertos. Una situación que se repite en otros países y continentes.

\section{La Nueva Ruta de la Seda (terrestre)}

La parte terrestre de la Nueva Ruta de la Seda constituye un gran corredor, y cuando esté finalizada conectará de este a oeste los dos extremos de Eurasia, y se verá complementada por otras vías de conexión. Es el trayecto que más atención despierta, debido a los acuerdos que aún están pendientes de firmar para hacerla realidad.

Para la construcción y ampliación tanto de infraestructuras propias de esta ruta, como de centros logísticos, ferrocarriles, gasoductos, oleoductos, etc., China 
pretende contar con el apoyo de más de 60 países. En Asia, cuenta con la colaboración de Mongolia y Rusia (al norte), de Kazajistán y Uzbekistán -grandes productores de petróleo y de gas natural- (al noroeste), de Paquistán, Irán y Turquía (al oeste), de Myanmar y Malasia (al sur), además de los países que ya forman parte de la ruta marítima. En Europa, la nueva vía terrestre aspira a abarcar varios países, entre ellos Serbia, Hungría, Polonia, Alemania, Italia, Holanda, Francia, España y Portugal, cuyos puertos ya están incorporados a la ruta marítima. Lo mismo se prevé hacer en África (figura 2).

\section{La Ruta terrestre y su eje principal}

El principal eje económico de esta vía conecta las regiones centrales y occidentales de China con importantes ciudades asiáticas y europeas. Tiene su punto de partida en el extremo oriental, en Xian, capital de la provincia de Shaanxi, en China Central, una ciudad muy bien comunicada con la capital Beijing (Pekín) y otras ciudades relevantes, como Wuhan (centro financiero, comercial y tecnológico), Chongqin (centro de negocios y financiero), Hangzhou (industria petroquímica), Chengdu (centro de Investigación, desarrollo e innovación $(I+D+I)$ ), Shilon y ciudades portuarias al este.

Su trazado y logística comprenden una robusta estructura que atraviesa China en dirección sudeste-noroeste hasta alcanzar su frontera occidental con Kazajistán y Kirguistán, donde se bifurca en una rama al norte y otra rama al sur, formando una elipse que guarda en su centro los mares Caspio, Negro y Azov, la cordillera del Cáucaso y las llanuras rusas de la cuenca del río Volga, regiones de gran interés estratégico y con grandes reservas de petróleo y gas natural.

La rama norte de este eje principal es la más importante porque conecta, en la actualidad, el extremo-oriente chino con Moscú, Europa Centro-oriental (Polonia, Alemania) y también Reino Unido. Después de atravesar el territorio chino, enlaza las ciudades chinas de Urumchi y de Alashankou con Astaná (capital de Kajaquistán), y la ciudad de Kazán, un importante centro industrial, financiero, comercial y turístico de Rusia, situado a orillas del río Volga, en la frontera rusa entre Europa y Asia. Desde este punto, la comunicación se hace a través de la red ferroviaria que conecta Moscú con Minsk, Varsovia, Berlín, Duisburg y los puertos de Hamburgo, Róterdam, Amberes y Londres (figura 3), ciudades que cuentan con 
infraestructuras vitales para el funcionamiento de esta ruta, como centros logísticos y de distribución de mercancías provenientes de China.

Figura 3 - Principal eje terrestre de la Ruta de la Seda y su rama norte (en color rojo)

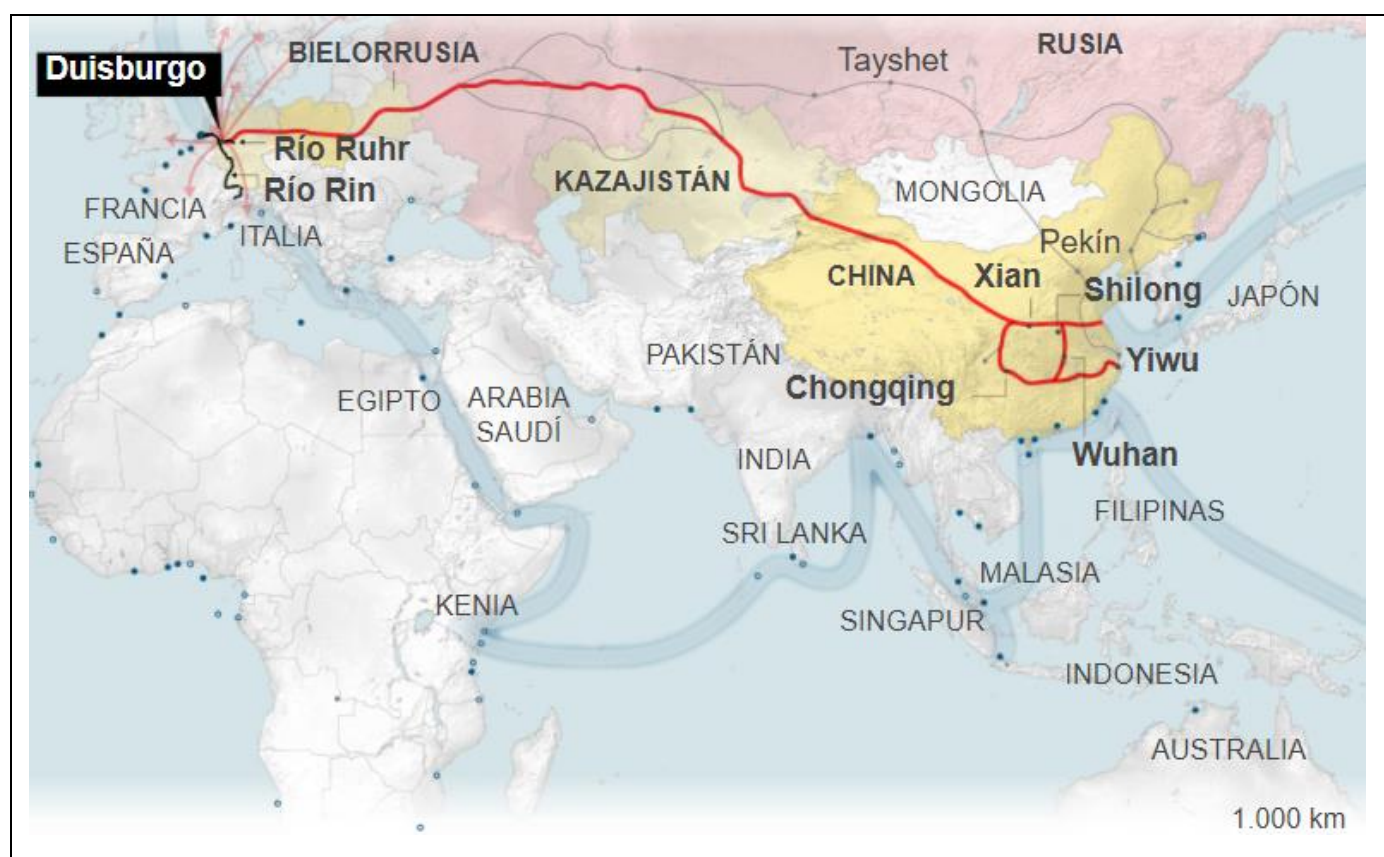

Fuente: Instituto Mercator para estudios sobre China (MERICS). Adaptado por los autores. Disponible en <https://elpais.com/internacional/2020-08-12/no-hay-pandemia-que-frene-al-tren-chino-enduisburgo.html>. Acceso 10 jul 2020

La rama sur de este principal eje, en gran parte en construcción o en proyecto, posee como objetivo comunicar el territorio chino con el Golfo Pérsico (Irán), Asia Menor (Turquía), Europa Oriental, Central y Meridional. Comienza en Alashankou, una ciudad china fronteriza conectada con la ciudad de Almaty (Kajaquistán) y con Tashkent (capital de Uzbekistán), únicos países, a excepción de Rusia, que pueden proveer de energía a China por medio de oleoductos o gasoductos directos. A continuación, en la rama sur se incorporan una red de ciudades iraníes (Mashad, Gorgán y Teherán), turcas (Ankara y Estambul) y europeas: Belgrado (Servía), Budapest (Hungría), Nuremberg (Baviera, Alemania), Estrasburgo, con una rama a Marsella (Francia), Bilbao y Madrid (España), éstas últimas ya conectadas por ferrocarril (figura 4). 
Figura 4 - Principal eje terrestre de la Ruta de la Seda y su rama sur (en color rojo)

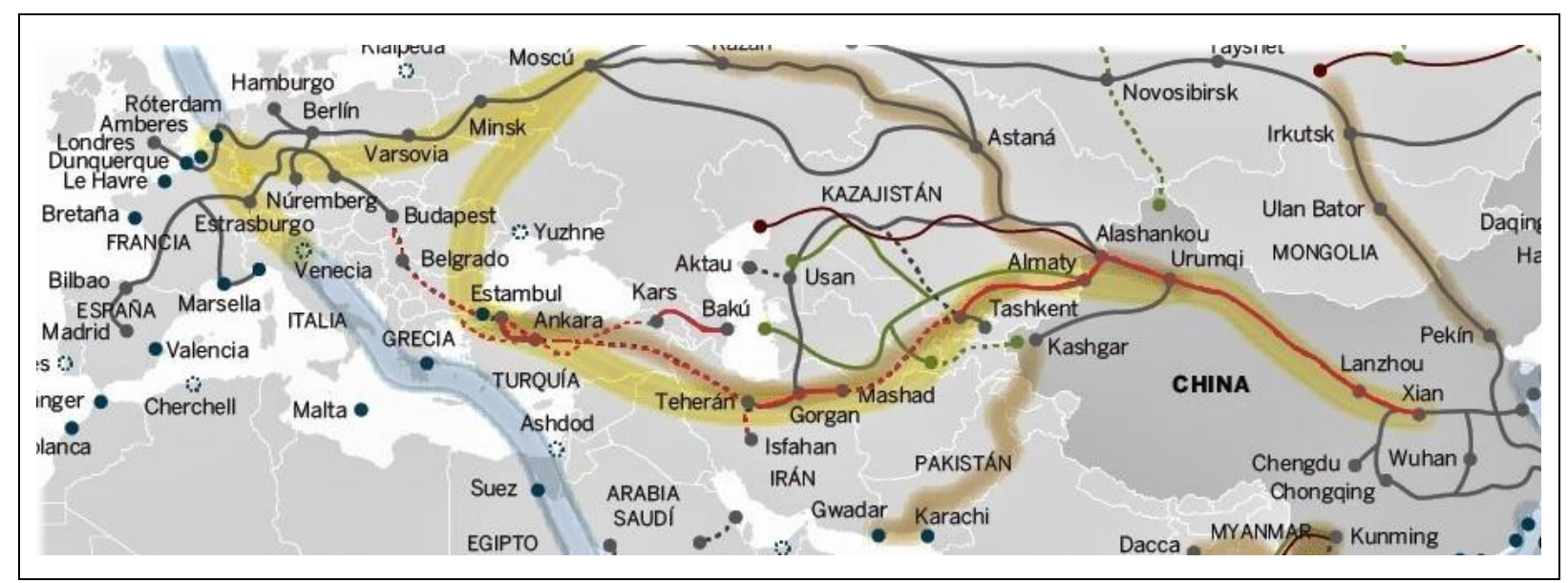

Fuente: Elaborado por los autores a partir de Instituto Mercator para estudios sobre China (MERICS).

En ambos tramos de la Nueva Ruta de la Seda, se construyen grandes hubs (intercambiadores, centros logísticos, puntos de conexión o nodos), desde los que se distribuyen mercancías chinas para las demás regiones europeas.

Entre el abanico de opciones, destaca la "ruta más larga del mundo", que desde 2014 cruza más de 13.000 kilómetros en 16 días para enlazar la ciudad de Yiwu (China) con Madrid (España). Lo realiza un convoy con más de 500 metros de longitud que llega a Madrid repleto de productos tecnológicos y de consumo, con destino al polígono Cobo Calleja, el mayor centro comercial de empresarios chinos de toda Europa, situado en la localidad madrileña de Fuenlabrada, y que regresa a China con jamones, aceite de oliva, vino, productos industriales y artículos de lujo (Martiarena, 2018) (figura 5). 
Figura 5 - Trayecto realizado por el tren Yiwu-Madrid

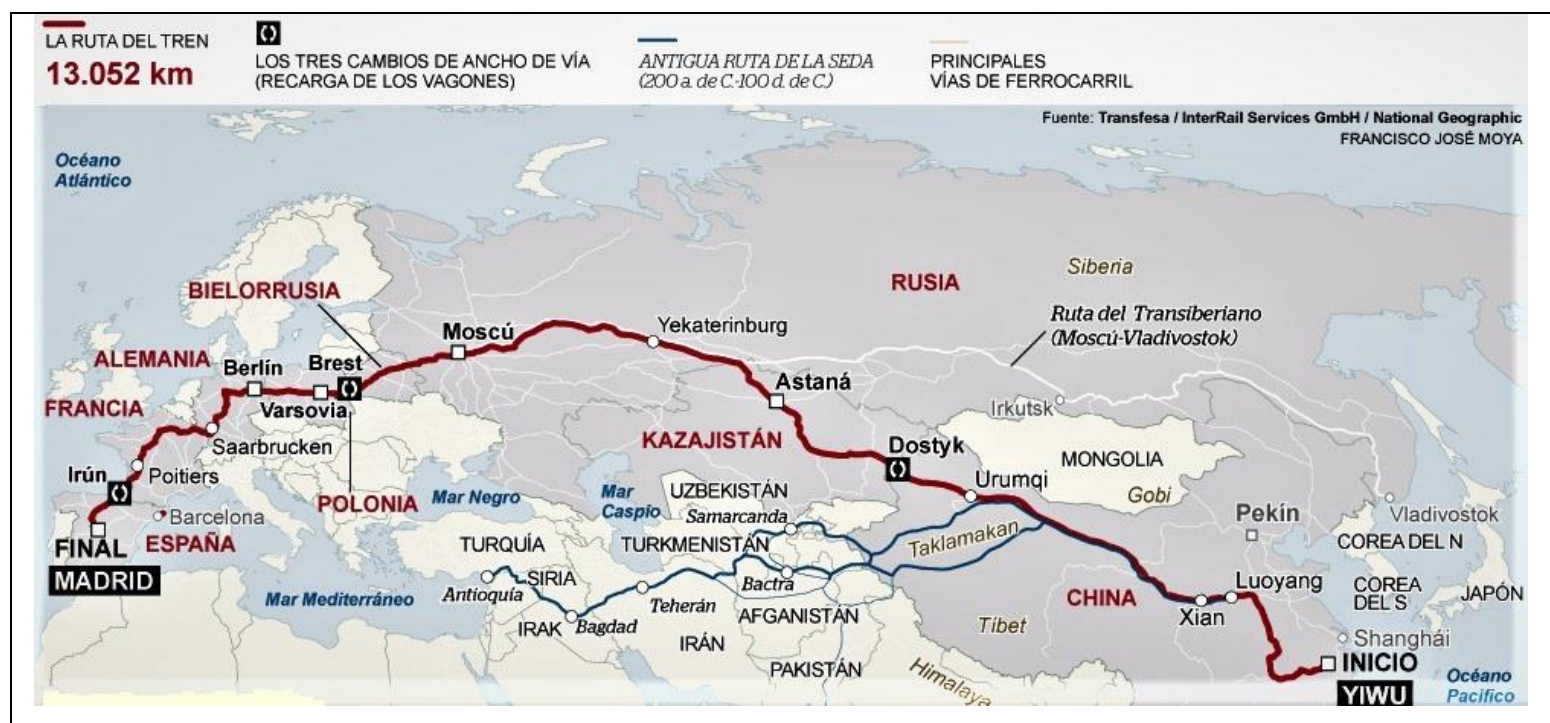

Fuente: Real Instituto Elcano. Disponible en <https://blog.realinstitutoelcano.org/nueva-ruta-de-laseda-empresas-espanolas/>. Acceso 10 jul 2020

Por este principal eje ferroviario, se transportaron en 2018, más de 350.000 contenedores entre China y Europa (Torrent, 2020). A pesar de representar solo un $2 \%$ del total de mercancías transportadas a través de la ruta marítima, su incremento en los últimos años ha sido mayor que el de ésta, lo que nos lleva a pronosticar que, dentro de una o dos décadas este porcentaje podrá incrementarse considerablemente. Esto sucederá a medida que se modernicen los tramos más deficientes, se adapten los diferentes anchos de vía existentes a lo largo de trayecto, se resuelvan los problemas rusos de aduanas respecto a los productos agroalimentarios de la Unión Europea, y se amplíen las estructuras logísticas. Un nuevo escenario en el que "la reducción del tiempo y de los costes del transporte ferroviario, aumentaría la competitividad de esta vía especialmente para mercancías sensibles a la humedad, perecederas o de alto valor y que no compensase llevar en avión por su volumen o peso" (Esteban y Otero-Iglesias, 09/04/2015).

\section{Otras ramificaciones importantes de la Nueva Ruta de la Seda terrestre}

Además del eje principal, el gobierno chino está construyendo otros tres corredores económicos. Uno de ellos tiene origen en la capital Pekín y se dirige a la capital de Mongolia, Ulán Bator, finalizando entre las ciudades rusas de Irkutsk y Tayshet a las orillas del lago Baikal con grandes reservas de petróleo y gas natural y de donde parten extensos oleoductos y gasoductos en forma de arcos, hacia Daqin y Harbín, principales ciudades de Manchuria, y a Vladivostok y Najodka (Extremo 
Oriente ruso), con la finalidad de atender la demanda energética urbana e industrial de estas regiones (figura 2).

Otro de estos corredores, parcialmente en construcción, está localizado al sur y tiene como principal propósito el desarrollo económico de la provincia sureña de Yunnan, conectándola, a través de su capital Kunming, con dos ramas de esta ruta. La oriental (sentido norte-sur), pretende conectar, a través de ferrocarril, Kunming al norte de Laos, Bangkok (Tailandia), Malasia y Singapur. La occidental (dirección leste-oeste) comunica Kunming con el norte de Myanmar y Dacca (Payra Port), situado en el mayor delta fluvial del mundo, en la desembocadura del río Ganges, en Bangladesh. Entre estas dos vías, y cortando el territorio de Myanmar, se encuentran otras dos iniciativas chinas, un oleoducto y un gaseoducto que enlazarán Kunming con los puertos de Sitwe y Payra en el litoral norte de Myanmar (figura 2).

Un tercer corredor económico está proyectado al sur del eje principal de la Ruta de la Seda y asegurará a China un acceso directo al Mar Arábigo. Se inicia en el extremo occidental chino, en el importante centro político y económico de Kasgar, situado en la Región Autónoma de Uigur de Xinjiang, a unos 200 quilómetros de la frontera con Kirguistán. Su recorrido previsto pasará por la región de Cachemira, disputada entre India, Paquistán y China -motivo por el que el gobierno indio se opone a su construcción-, y tendrá como destino dos puertos paquistanís incluidos en la Ruta Marítima de la Seda: Karachi y Gwadar (figura 2), este último gestionado por la empresa China Overseas Ports Holding Company (COPHC).

En Gwadar, chinos y paquistaníes también cuentan con Arabia Saudí para la construcción de un complejo petrolero que ocupará 70.000 hectáreas y para el que se prevé una inversión de 10.000 millones de dólares (AA News, 11/10/2018).

En la figura 6 se observan los principales proyectos que China tiene en Pakistán, y que comprenden desde refinarías, oleoductos, plantas nucleares y de energías renovables, hasta diferentes modalidades de infraestructuras de movilidad, que consideramos, ponen en riesgo la soberanía pakistaní. 
Figura 6 - El ambicioso plan chino en Pakistán

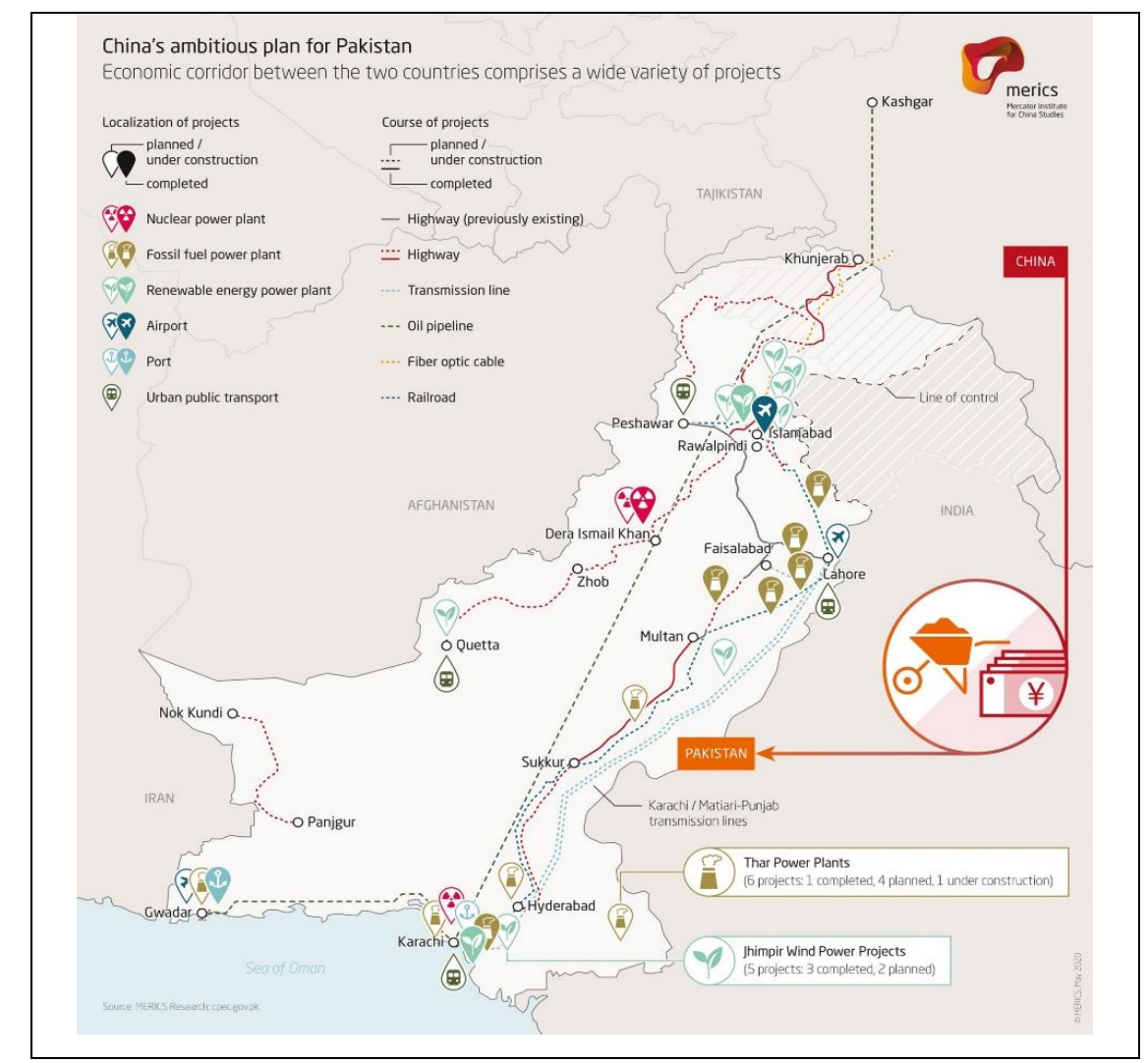

Fuente: Instituto Mercator para estudios sobre China (MERICS). Disponible en $<$ https://merics.org/en>. Acceso 25 jun 2020

También como parte de este proyecto, está en construcción en Kasgar una de las ramas que se añadirá a la importante red de gasoductos existentes en los territorios de Kazajistán, Kirguistán, Tayikistán y Uzbekistán, cuyo recurso, en su mayoría, se extrae de la región del Mar Caspio.

Estos y otros acuerdos bilaterales de cooperación entre estos países también han sido fundamentales para la integridad territorial de China, debido a los vínculos étnicos, religiosos y culturales existentes entre las poblaciones turcas de Kazakstán y Uzbekistán, principalmente, la población uigur y otras minorías étnicas de la región autónoma china de Uigur Xinjiang, donde ha habido constantes brotes separatistas (Anguiano, 2001, p. 275).

En su conjunto, se trata de un ambicioso plan que el gobierno chino prevé que esté en pleno funcionamiento y totalmente consolidado en el año de 2049, cuando la República Popular China completará 100 años desde su fundación. 


\section{Consideraciones finales}

Hemos visto como los principales objetivos expansionistas y geoestratégicos de China, están estrechamente vinculados a la iniciativa de la Nueva Ruta de la Seda, a través de la cual pretende ampliar sus áreas de influencia.

A pesar de esto, China ha insistido en que One Belt One Road (OBOR) no es un proyecto geopolítico, sino un producto de cooperación inclusivo, que pretende promover el desarrollo del orden económico internacional en dirección a la igualdad, el beneficio común y la cooperación, tanto para conformar un sistema comercial internacional justo, como para abordar conjuntamente los desafíos mundiales (13ำ Plan Quinquenal, Capítulo 52).

Pero cabe preguntarse si esto es realmente así. ¿Cuál habría sido el motivo por el que China puso en marcha una cooperación bilateral con 16 estadosmiembros de la Unión Europea, para la construcción y modernización de sus autopistas, redes ferroviarias, aeropuertos y puertos marítimos, sin consultar con su organismo unitario? La falta de una respuesta convincente suscita dudas sobre el contenido de los acuerdos y la relación de estos países con el gigante asiático.

Los discursos de sus mandatarios resaltan que la Nueva Ruta de la Seda, consolidada mediante tratados multilaterales y bilaterales, firmados por gobiernos y organizaciones regionales e internacionales, tiene como objetivo mantener el orden y la paz mundial, creando estabilidad en zonas conflictivas, situadas a lo largo de esta Ruta, en las que incluyen sus regiones autónomas de Tíbet y de Uigur de Xinjiang, y países como Afganistán, Pakistán, Irak, etc.

A pesar de esta y otras declaraciones chinas, un gran número de analistas coinciden en que la Nueva Ruta de la Seda es un instrumento para lograr las aspiraciones expansionistas chinas por las distintas regiones por las que transcurre, lo que supondría importantes cambios en el orden geopolítico internacional.

Entre las razones que destacan está la geoestratégica, tanto mediante el enfrentamiento con EEUU y sus aliados asiáticos, Japón e India, como a través de los conflictos de influencia o de dominio que probablemente surgirán, ya que China competirá de modo directo con todos los países con los que mantiene acuerdos para la construcción de la Nueva Ruta de la Seda, incluyendo en esta vorágine, las rutas polares que comienzan a ser asequibles debido al calentamiento del planeta. También sucedería en las áreas limítrofes con la Unión Europea, principalmente en 
el África Nord sahariana y Oriente Medio, pudiendo acarrearle la pérdida de su papel central en esta área de influencia.

Asimismo, debemos subrayar el incremento de la influencia cultural, empresarial y económica china, en especial entre los países menos desarrollados. La aceptación de que la "senda china" es la más acertada, podrá provocar la expansión de un modelo económico, muy cuestionado por varias razones. Entre ellas, las precarias relaciones de trabajo, los problemas medioambientales y la asimetría comercial entre China y los países más pobres de esta Ruta, a los que los trenes llegan cargados de productos chinos y de los que vuelven casi vacíos.

Respecto a las consecuencias socio económicas, la Nueva Ruta de la Seda se propone, según el 13ำ Plan Quinquenal, sobre todo, el desarrollo de los países con infraestructuras débiles, como Kazajistán, Kirguistán, Tayikistán y Uzbekistán. Cabe preguntarse: ¿Estas infraestructuras se utilizarán para desarrollar estos países económica y socialmente, o tendrán como único fin, suministrar materias primas y energía a China? lo que de hecho supondría un modo de neocolonialismo. ¿La incursión de estos países en el modelo económico chino aumentará las desigualdades sociales, como está ocurriendo en la propia China, o traerá beneficios sociales amplios? Además, ¿es posible que las enormes inversiones chinas, como sucede en Kenia, continúen generado una considerable deuda en muchos países participantes?

Por estas y otras razones es fundamental desvelar la esencia de un proyecto que, al presentarse, como la alternativa china al modelo occidental, posee varias y complejas facetas. Al mismo tiempo que difunde una diplomacia de buena vecindad y de 'socio del diálogo y de la cooperación' y utiliza también la crisis de la Covid-19 para aproximarse a varios países, a través de la donación de material sanitario (Zaar, García-Ávila, 2020; Zaar, 2020), decide liderar iniciativas de gran calado en la escena internacional que poseen en su cerne procesos contradictorios.

Un análisis profundo del rumbo de las políticas chinas más recientes posibilitaría prever, cómo en este nuevo orden internacional, en el que China despunta, la libertad, la soberanía y la igualdad de condiciones de los Estados en sectores estratégicos será dibujada.

A guisa de conclusión se puede subrayar que todos los países que deseen sumarse a este ambicioso proyecto, definido como Nueva Ruta de la Seda, deben hacerlo desde una posición responsable y crítica que contribuya a darle una forma, 
mediante la que se preserve la igualdad de derechos en las futuras tomas de decisiones en lo que a ella concierne.

\section{REFERENCIAS}

AGENCIA DE NOTICIAS XINHUA. EI 13 Plan Quinquenal para el Desarrollo Económico y Social Nacional de la República Popular China. Beijing, 17 de marzo 2016.

ANGUIANO, Eugenio. Diplomacia de la república Popular China. China contemporánea: la reconstrucción de un país desde 1949. México: El Colegio de México, 2001. DOI: 10.2307/j.ctv3dnnv8.

BELLUGA CAPILLA, Hiscio; GÓMEZ DE ÁGREDA, Ángel. Made in China. $<$ https://docplayer.es/64418470-Made-in-china-hiscio-m-belluga-capilla-y-angel-gomez-deagreda.html>.

BREGOLAT, Eugenio. En torno al renacimiento de China. Lleida: Ediciones de la Universitat de Lleida, 2014, $<$ https://books.google.es/books?redir_esc=y\&hl=es\&id=9HhpBgAAQBAJ\&q=China\#v=snipp et $\& \mathrm{q}=$ China $\& \mathrm{f}=\mathrm{false}>$.

CALLAHAN, Willian. EE.UU. y China, potencias en pugna. Vanguardia Dossier, 02/10/2019 $<$ https://www.lavanguardia.com/vanguardia-dossier/20190708/463366937429/china-

2035.html>.

CORNEJO, Romer Alejandro. China: una revisión de cincuenta años de historia. China contemporánea: la reconstrucción de un país desde 1949. México: El Colegio de México, 2001. DOI: 10.2307/j.ctv3dnnv8.

COSCO SPAIN. Cosco Spain es la nueva denominación de Nuatum Ports, 29/03/2019 $<$ https://coscospain.com/cosco-shipping-ports-spain-es-la-nueva-denominacion-de-noatumports/>.

El

País, 30/11//2018<https://elpais.com/economia/2018/11/30/actualidad/1543600537_893651.html> y $08 / 12 / 2020<$ https://elpais.com/internacional/2020-08-12/no-hay-pandemia-que-frene-altren-chino-en-duisburgo.html>.

ESTEBAN, Mario; OTERO-IGLESIAS, Miguel. ¿Qué podemos esperar de la nueva Ruta de la Seda y del Banco Asiático de Inversión en Infraestructuras liderados por China? Real Instituto

Elcano,

09/04/2015

$<$ http://www.realinstitutoelcano.org/wps/portal/rielcano_es/contenido?WCM_GLOBAL_CONT EXT=/elcano/elcano_es/zonas_es/asia-pacifico/ari18-2015-esteban-otero-que-podemosesperar-nueva-ruta-de-la-seda-y-banco-asiatico-de-inversion-en-infraestructuras-lideradospor-chinas.

Eurochinabridge.com. One Belt Obe Road. El sueño chino y su impacto sobre Europa. $\begin{array}{lllll}\text { Eurochinabridge, } & 27 & \text { de diciembre } & \text { de } & 2017\end{array}$ $<$ https://www.eurochinabridge.com/noticias2/139-economia/366-one-belt-one-road-el-suenochino-y-su-impacto-sobre-europas. 
GARCÍA SÁENZ, Marina. La nueva ruta de la seda. La vanguardia, 19/04/2019 $<$ https://www.lavanguardia.com/participacion/lectores-

corresponsales/20190416/461601385456/nueva-ruta-seda-china.html>.

GOMÀ, Daniel. El XVII Congreso del Partido Comunista Chino y el inicio de la sucesión de Hu Jintao: Preparando la quinta generación de dirigentes comunistas. Biblio 3W Revista Bibliográfica de Geografía y Ciencias Sociales, Universidad de Barcelona, Vol. XIII, oㅡ 780, 5 de abril de 2008 <http://www.ub.edu/geocrit/b3w-780.htm>.

HARVEY, David. Breve historia del neoliberalismo. Madrid: Akal, 2007.

INSTITUTO MERCATOR PARA ESTUDIOS SOBRE CHINA (MERICS). $<$ https://merics.org/en>.

INSTITUTO MERCATOR PARA ESTUDIOS SOBRE CHINA (MERICS). The BRI in Paquistan: China's flagship economic corridor <https://merics.org/en/analysis/bri-pakistanchinas-flagship-economic-corridor>.

LACOSTE, Yves. Geopolítica. La larga historia de hoy. Madrid: Síntesis, 2009.

LAURANCE, William. The dark legacy of China's drive for global resources. Yale Environment 360, 28/03/2017 <https://e360.yale.edu/features/the-dark-legacy-of-chinasdrive-for-global-resources>.

MARTIARENA, Asier. Yiwu-Madrid, el 'tren de la seda' más largo del mundo que no pierde fuelle. La Vanguardia, $28 / 11 / 2018$ $<$ https://www.lavanguardia.com/local/madrid/20181128/453149870215/yiwu-madrid-rutaseda-larga-mundo.html>.

MÜLLER-MARKUS, Christina. One Belt, One Road: el sueño chino y su impacto sobre Europa. Barcelona: CIDOB, 05/2016 < https://www.cidob.org/publicaciones/serie_de_publicacion/notes_internacionals/n1_148_one _belt_one_road_el_sueno_chino_y_su_impacto_sobre_europa/one_belt_one_road_el_suen o_chino_y_su_impacto_sobre_europa>.

OFICINA ECONÓMICA Y COMERCIAL DE LA EMBAJADA DE ESPAÑA EN PEQUÍN. Made in China 2025, octubre $2016<$ https://www.icex.es/icex/es/navegacionprincipal/todos-nuestros-servicios/informacion-de-mercados/paises/navegacion-principal/elmercado/estudios-informes/DOC2016671546.html?idPais=CN >.

PIQUÉ, Josep. Malaca: centro de gravedad y campo de batalla. El Confidencial, 10/02/2020 <https://blogs.elconfidencial.com/mundo/tribuna-internacional/2020-0218/malaca-centro-gravedad-politica-exterior-comercio-exportaciones_2458511/>.

QUINTANA, Laura de la. China abre una nueva Ruta de la Seda en que invertirá 8 billones de dólares. El Economista, 14/05/2018 <https://www.eleconomista.es/mercadoscotizaciones/noticias/9135375/05/18/China-abre-una-nueva-Ruta-de-la-Seda-en-la-queinvertira-8-billones-de-dolares.html>.

REAL INSTITUTO ELCANO <https://blog.realinstitutoelcano.org/nueva-ruta-de-la-sedaempresas-espanolas/>. 
SIMON, Bernhard. ¿Pude competir la Nueva Ruta de la Seda con la Ruta Marítima? Novologística.com <https://novologistica.com/maritimo-y-aereo/puede-competir-la-nuevaruta-de-la-seda-con-la-ruta-maritima/>.

TORRENT, Jordi. La Nueva Ruta de la Seda: una incógnita tras la Covid-19. Piernext, 04/04/2020 <https://piernext.portdebarcelona.cat/movilidad/la-nueva-ruta-de-la-seda-unaincognita-tras-el-covid-19/>.

Wikipedia.org.<https://es.wikipedia.org/wiki/Ruta_de_la_seda\#: :text=La\%20Ruta\%20de\%2 Ola\%20Seda\%20fue\%20una\%20red\%20de\%20rutas,\%2C\%20Turqu\%C3\%ADa\%2C\%20Eu ropa\%20y\%20\%C3\%81frica.>.

ZAAR, Miriam Hermi; GARCÍA ÁVILA, Manuel-Blas García Ávila. La Covid-19 en España y sus primeras consecuencias. Espaço e Economia [Online], 17|2020, posto online no dia 06 abril 2020 <http://journals.openedition.org/espacoeconomia/10142>, DOI : https://doi.org/10.4000/espacoeconomia.10142.

ZAAR, Miriam Hermi. A geografia da crise Covid-19 na União Europeia. RIBEIRO, Wagner Costa (Org.) Covid-19: passado, presente e future. São Paulo: FFLCH/USP, 2020. pp. 6492. En publicación.

Zenglein, Max, J. Europe should realize it has leverage to stand up to China, Asian Review, 10/07/2020 <https://asia.nikkei.com/Opinion/Europe-should-realize-it-has-leverage-to-standup-to-Chinas.

\section{NOTAS DE AUTOR}

\section{CONTRIBUIÇÃO DE AUTORIA}

Miriam Hermi Zaar - Concepção. Coleta de dados. Análise de dados. Elaboração do manuscrito. Revisão e aprovação da versão final do trabalho

Manuel-Blas García Ávila - Concepção e elaboração do manuscrito. Coleta de dados. Participação ativa da discussão dos resultados. Revisão e aprovação da versão final do trabalho.

\section{FINANCIAMENTO}

Não se aplica.

\section{CONSENTIMENTO DE USO DE IMAGEM}

Não se aplica.

\section{APROVAÇÃO DE COMITÊ DE ÉTICA EM PESQUISA}

Não se aplica.

\section{CONFLITO DE INTERESSES}

Não se aplica.

\section{LICENÇA DE USO}

Este artigo está licenciado sob a Licença Creative Commons CC-BY. Com essa licença você pode compartilhar, adaptar, criar para qualquer fim, desde que atribua a autoria da obra.

\section{HISTÓRICO}

Recebido em: 19-09-2020

Aprovado em: 11-10-2020 